\title{
Investigation of the Effects of Lavender Oil Aromatherapy to Prevent Preoperative Anxiety in Patients Scheduled for Tympanoplasty
}

\author{
Oguz Kadir Egilmez ${ }^{1 *}$ iD, Mehmet Guven ${ }^{1}$ iD, Ayten Yilmaz² iD, Ebru Mihriban Guven³ iD) \\ Mahmut Emre Gundogan ${ }^{1}$ iD \\ ${ }^{1}$ Department of Otorhinolaryngology, Sakarya University Training and Research Hospital, Sakarya, Turkey \\ ${ }^{2}$ Traditional and Complementary Medicine Application and Research Center, Sakarya University Training and Research \\ Hospital, Sakarya, Turkey \\ ${ }^{3}$ Health Sciences High School, Sakarya University, Sakarya, Turkey
}

*Corresponding Author: Oguz Kadir Egilmez, e-mail: oguzegilmez@gmail.com

Received: 30.08.2021

Accepted: 13.10.2021

\begin{abstract}
Objective: Anxiety is a common problem before surgical procedures. The effectiveness of aromatherapy in preoperative anxiety control has been demonstrated by some studies. The aim of this study is to investigate the effects of lavender oil inhalation on anxiety levels in patients before ear surgery.

Material-Method: The study was conducted in the Otorhinolaryngology clinic of a tertiary university hospital. A total of 68 patients (34 in the study group, 34 in the control group) who were scheduled for tympanoplasty operation were included in the study. Inhalation of lavender oil was used in the patients in the study group before the operation, and liquid paraffin was used in the control group. A personal information form and State-Trait Anxiety Scale (STAI) were used to collect data. Results: In the study group, the mean STAI pre-test and post-test mean scores were $44.50 \pm 12.38$ and $36.48 \pm 10.73$, respectively, and there was a statistically significant difference $(\mathrm{p}<0.05)$. These values were $45.60 \pm 12.35$ and $41.83 \pm$ 10.78 , respectively, in the control group, and the difference was not statistically significant ( $\mathrm{p}>0.05)$. Also, when the posttest STAI mean scores were evaluated between the study and control groups, a statistically significant difference was found ( $\mathrm{p}$ $<0.05)$.
\end{abstract}

Conclusion: Lavender oil inhalation before ear surgery has been found to reduce anxiety levels in patients.

Keywords: Inhalation Aromatherapy, Lavender Oil, Anxiety, Tympanoplasty

\section{INTRODUCTION}

Preoperative anxiety developing in patients waiting for a surgical intervention is a common problem in health centers. Surgical procedures may cause patients to be confronted with physical and psychological problems. Patients may have preoperative anxiety with emotional stress due to reasons such as fear of losing their job and the thought of burdening other family members. High preoperative anxiety levels may cause patients to feel pain in the postoperative period ${ }^{1,2}$.

Consequently, the use of anesthetic and narcotic drugs increases, and the hospitalization period is prolonged. In addition, delayed wound healing in postoperative period and weakening of the capacity to combat with infection can be observed ${ }^{3}$. Therefore, it is very important to diminish the anxiety degrees of patients prior to surgical intervention.

Ear-related surgeries are frequently performed in ear, nose and throat clinics. In chronic pathologies related to the ear, which is an important sensory organ, patients who do not benefit from medical treatment may require surgery. In the postoperative period, rapid recovery is essential for the patient to return to their normal daily life. In addition to preoperative prophylactic measures, the patient should also be psychologically ready for surgery in order not to delay wound healing.

In the preoperative period, it may be difficult for the patient to control the fear of surgery on their own. For this, the effectiveness of aromatherapy before surgery has been shown in some studies ${ }^{3-7}$. Our study was planned to determine the outcomes of 


\author{
Volume: 2 Issue: 3 \\ Year: 2021 \\ DOI: $10.53811 /$ ijtcmr.988785
}

International Journal of Traditional and Complementary

Medicine Research
Publisher
Duzce University lavender oil inhalation on preoperative anxiety in patients scheduled for tympanoplasty.

\section{MATERIALS AND METHODS}

Our experiment was begun after the approval of the local ethics committee and Republic of Turkey Ministry of Health Traditional, Complementary and Functional Medicine Practices Ethics Committee (No: 20/07 / 2020-37106781-000-199755). All the procedures were done in accordance with the ethical standards of the Sakarya University Ethics Committee on human experimentation and with the Helsinki Declaration. The research was a randomized controlled study and an experimental research design was used. The study was completed with two groups: control (placebo) and experimental (lavender oil) groups.

\section{Population, sampling and procedure}

The population of this study was composed of patients who were diagnosed with chronic otitis media (COM) in the Ear Nose and Throat (ENT) Diseases Clinic of Sakarya University Training and Research Hospital and who were planned for tympanoplasty surgery and were hospitalized in the ENT service for this reason. G*Power 3.1.9.4 program was used to calculate the number of samples predicted for the study. In the calculation, the sample size was determined as 34 persons for each group with the assumption of 0.5 effect value at $95 \%$ confidence interval. In the study, a randomization method was used for the assignment of participants to the control and experimental groups.

\section{Inclusion criteria}

- Being over the age of 18 ,

-Tympanoplasty operation planned with the diagnosis of COM,

- Not having cognitive, verbal and auditory problems that may affect communication,

- Not been diagnosed with psychiatric illness,

- Being able to smell odors and have no problem with smell,

- Patients who are not allergic to odors were included in the study.

\section{Exclusion criteria from the study}

- Younger than 18 years of age,

- Having a problem in communicating,

- Having a diagnosis of psychiatric illness and a history of sedative drug use,
- Having a pathology in the nose that prevents smelling,

- Patients who did not sign a voluntary consent form and did not want to attend to the experiment were excluded from the research.

\section{The implementation phase of the research Preparation phase}

Before starting our experiment, placebo solution and lavender oil to be used in the study were prepared by a pharmacist in the form of 68 similar bottles with labels A (34) and B (34). In the study, liquid paraffin $(100 \%$ purity) was used in the placebo group and lavender oil $(100 \%$ pure Lavandula angustifolia diluted with distilled water at a ratio of 1:10) was used in the experimental group. Throughout the study, the contents of the prepared solutions were not known by the participants or the researcher and statistician who would carry out the study, and the unbiased evaluation of the study was provided by triple blinding.

\section{Implementation of the research}

In the implementation phase of the study, patients who were diagnosed with COM and hospitalized for tympanoplasty operation in the ENT Diseases Clinic of Sakarya University Training and Research Hospital were determined and the compliance of the patients with the inclusion and exclusion criteria in the study was ascertained. Participants were instructed about the purpose, duration and scope of the study, and informed consent was obtained, stating that their participation was voluntary. In order to predict the allergic responses of the participants who were eligible for inclusion and volunteering to participate in this study, a sufficient amount of placebo and lavender oil in a dropper bottle were applied to the inner side of the forearm and this was observed in terms of allergic conditions such as rash, fever and itching. Sociodemographic findings of the participants who did not develop an allergic reaction were recorded, and the "State-Trait Anxiety Inventory" (STAI), which is frequently used in the literature regarding anxiety and defined by Spielberger et al., was applied 2 hours before the operation ${ }^{8}$. After the scale was completed, 5 drops of lavender oil or liquid paraffin for placebo were dropped onto a $5 \times 5 \mathrm{~cm}$ sterile gauze and the participants were asked to smell this for 5 minutes from a distance of $8-10 \mathrm{~cm} .20$ minutes after the end of the sniffing process, the STAI scale was applied again and the values were recorded (Figure-1). 
Volume: 2 Issue: 3

Year: 2021

DOI: $10.53811 /$ ijtcmr.988785

\section{FLOW CHART}

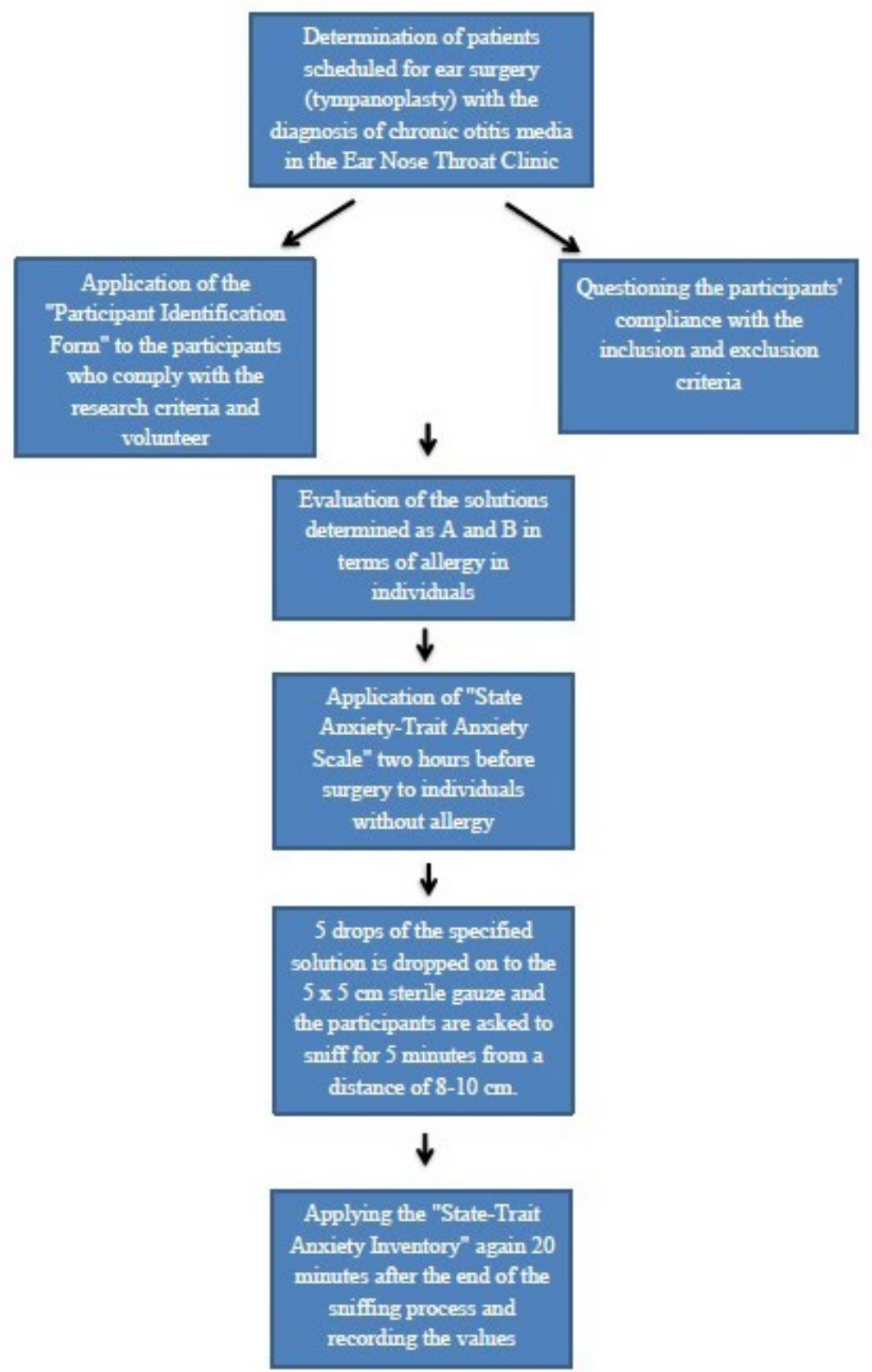

Figure 1. Flow chart for the implementation of the research

\section{Participant identification form}

This form was composed of questions regarding age, gender, height, weight, marital status, educational status, occupation, economic status, hospitalization history, surgery history and aromatherapy use history of the participants.

\section{State-trait anxiety inventory (STAI)}

One of the most frequently used anxiety inventories in psychological research is STAI. It has two subinventories; each containing 20 items. The initial sub-inventory determines state anxiety (S-STAI) showing how a person is feeling at that time. The second sub-inventory determines trait anxiety (TSTAI) showing how they usually feel. Subinventory scores range of 20 to 80 . High points for the all two sub-inventories show a higher level of anxiety. A cut-off score of 39-40 points has been proposed for STAI to distinguish clinically compelling manifestations. 


\author{
Volume: 2 Issue: 3 \\ Year: 2021 \\ DOI: $10.53811 /$ ijtcmr.988785
}

International Journal of Traditional and Complementary

Medicine Research
Publisher
Duzce University

\section{Evaluation of data}

SPSS for Windows v 22.00 (IBM Co., Armonk, New York, USA) program was used for statistical analysis and the evaluation of the data obtained. Descriptive statistics were mean \pm standard deviation for continuous data and numbers and percentages for discrete data. The suitability of normal distribution was evaluated with the Kolmogorov-Smirnov test, and correlations between two groups were performed with t-test or Mann Whitney $U$ test in independent groups and paired sample tests for the same group according to the normal distribution of variables. $\mathrm{p}<0.05$ was accepted as statistically significant.

\section{RESULTS}

Data associated with gender, age, marital condition, employment condition, place of residence, surgery history and aromatherapy experience of the patients are given in Table-1. Considering demographic characteristics, there was no statistically significant difference between the control and study groups.

Table 1. Demographic characteristics of the patients included in the study

\begin{tabular}{|c|c|c|c|}
\hline & $\begin{array}{l}\text { Study group }(n=34) \\
\text { Mean } \pm \text { Std }\end{array}$ & $\begin{array}{l}\text { Control }(n=34) \\
\text { Mean } \pm \text { Std }\end{array}$ & Analysis (p) \\
\hline Age & $48.02 \pm 15.38$ & $42.54 \pm 11.42$ & 0.314 \\
\hline \multicolumn{4}{|l|}{ Gender, $\mathbf{N}(\%)$} \\
\hline Female & $15(\% 44)$ & $13(\% 40)$ & 0.855 \\
\hline Male & $19(\% 56)$ & $21(\% 60)$ & 0.783 \\
\hline \multicolumn{4}{|l|}{ Marital Status, N (\%) } \\
\hline Married & $25(\% 73)$ & $26(\% 76)$ & 0.765 \\
\hline Single & $9(\% 27)$ & $8(\% 24)$ & 0.615 \\
\hline \multicolumn{4}{|l|}{ Employment Status, N (\%) } \\
\hline Yes & $27(\% 79)$ & $25(\% 73)$ & 0.416 \\
\hline No & $7(\% 21)$ & $9(\% 27)$ & 0.187 \\
\hline Place of residency, N (\%) & & & 0.565 \\
\hline Rural & $2(\% 6)$ & $1(\% 3)$ & \\
\hline Town & $7(\% 20)$ & $9(\% 26)$ & \\
\hline City center & $25(\% 74)$ & $24(\% 71)$ & \\
\hline Surgery History, N (\%) & & & 0.725 \\
\hline Yes & $14(\% 41)$ & $16(\% 47)$ & \\
\hline No & $20(\% 59)$ & $18(\% 53)$ & \\
\hline Aromatherapy History, N (\%) & & & 0.284 \\
\hline Yes & $2(\% 6)$ & $1(\% 3)$ & \\
\hline No & $32(\% 94)$ & $33(\% 97)$ & \\
\hline
\end{tabular}

$\mathrm{N}=$ number; Mean $\pm \mathrm{Std}=$ Mean value \pm standart deviation

Table-2 exhibits the values of the upper and lower degrees of STAI in the pre-test and post-tests of the patients in two groups. Although mean pre-test and post-test STAI points in the study group were 44.50 \pm 12.38 and $36.48 \pm 10.73$, respectively, and the difference was statistically significant ( $\mathrm{p}=0.007)$, it was $45.60 \pm 12.35$ and $41.83 \pm 10.78$ in the control group, respectively, and there was not a statistically significant difference $(\mathrm{p}=0.215)$.

Table 2. The lowest and highest values according to the State-Trait Anxiety Inventory (STAI) pre- test and post-test results applied to the patients in the study and control groups

\begin{tabular}{lccccc}
\hline & & \multicolumn{2}{c}{ Pre Test } & \multicolumn{2}{c}{ Post Test } \\
\hline Sub-scale & Highest and Lowest Ranks in the Questionnaire & Study group & Control & Study group & Control \\
\hline $\begin{array}{l}\text { State Anxiety } \\
\text { (S-STAI) }\end{array}$ & $20-80$ & $20-72$ & $20-70$ & $20-65$ & $20-69$ \\
$\begin{array}{l}\text { Trait Anxiety } \\
\text { (T-STAI) }\end{array}$ & $20-80$ & $27-66$ & $25-60$ & - & - \\
\hline
\end{tabular}




\author{
Volume: 2 Issue: 3 \\ Year: 2021 \\ DOI: $10.53811 /$ ijtcmr. 988785
}

International Journal of Traditional and Complementary

Medicine Research
Publisher
Duzce University
Mean pre-test STAI scores were $44.50 \pm 12.38$ in the study group and $45.6 \pm 12.35$ in the control group, and no statistically significant difference was found between the groups $(\mathrm{p}=0.658)$.
However, the mean post-test STAI scores were $36.48 \pm 10.73$ in the study group and $41.83 \pm 10.78$ in the control, and the difference was statistically significant between two groups $(\mathrm{p}=0.015)$ (Table-3).

Table 3. Comparison of S-STAI pre-test and post-test mean scores within and between groups

\begin{tabular}{lccc}
\hline & Study group $(\mathbf{n}=\mathbf{3 4})$ Mean \pm Std & Control $(\mathbf{n}=\mathbf{3 4})$ & Mean \pm Std \\
\hline S-STAI pre-test & $44.5 \pm 12.38$ & $45.6 \pm 12.35$ & 0.658 \\
S-STAI post-test & $36.48 \pm 10.73$ & $41.83 \pm 10.78$ & $\mathbf{0 . 0 1 5}$ \\
Analysis (p) & $\mathbf{0 . 0 0 7}$ & 0.215 & \\
\hline STAIs &
\end{tabular}

$\mathrm{STAI}=$ State-Trait Anxiety Inventory; $\mathrm{n}=$ number; Mean \pm Std $=$ Mean value \pm standard deviation

\section{DISCUSSION}

The outcomes of our study, whose goal is to investigate the responses of lavender oil on the anxiety levels of patients before tympanoplasty operation, are reviewed with the literature. In some previously published studies, it has been reported that patients experience anxiety while waiting for the surgical intervention. In their experiment, where Foley et al. explained various treatment options and surgical steps using the Apple iPad application in the preoperative period and investigated the effects of being informed about the basis of breast cancer, it was found that anxiety levels in patients were greater before and urgently after the surgery 9. Findık and Topçu ${ }^{10}$ examined the effect of the way of preparing the patient for surgical operation on the pre-operative anxiety degree and reported that the patients' anxiety levels fell before the surgery while waiting. Alike, in an experiment conducted by Şivgin et al. ${ }^{11}$, the impact of psychological and pharmacological premedication on pre-operative anxiety degree during elective operation were investigated and the outcomes indicated that patients had anxiety before surgeries. In the light of previous studies on preoperative anxiety, the average anxiety points of the questionnaires conducted in this period were found to be higher.

Lavender oil has in recent times been frequently used in inhalation aromatherapy and massage therapy ${ }^{12}$. There are many types of lavender. Among these species, Lavandula officinalis and Lavandula angustifolia have medicinal effects and are often used. With their inhalation, linalyl acetate and linalool are released in the body, thereby suppressing anxiety ${ }^{13}$. For this reason, lavender oil is used to diminish pain, reduce concern and depression levels, and relieve preoperative anxiety. Toda and Morimoto studied the effectiveness of lavender aromatherapy on chromogranin and cortisol degrees in the body and found that lavender had a stress-reducing effect on the body ${ }^{14}$. In the experiment conducted by Lehrner et al. ${ }^{1}$ related to the effectiveness of lavender oil and orange on concern degrees in patients before dental procedures, they concluded that lavender oil reduced anxiety. Umezu et al. ${ }^{15}$ examined the effects of the ingredients in lavender oil aromatherapy on anxiety and concluded that this effect was with the help of linalool. Shiina et al. ${ }^{16}$ studied the effectiveness of lavender oil aromatherapy on blood circulation and concluded that aromatherapy with lavender oil affects serum cortisol levels and thus reduces stress. In another experiment by Franco et al. ${ }^{17}$ investigating the effectiveness of aromatherapy applying lavender oil before breast cancer operation on concern degrees, it was found that the reduction in anxiety levels in the preoperative period in the group that received lavender oil aromatherapy was statistically significant. In the review conducted by Boehm et al. ${ }^{18}$, the effectiveness of adjuvant aromatherapy on cancer patients were investigated, and the authors concluded that cancer patients' anxiety was significantly reduced after aromatherapy. Similarly, in another study exploring the anxiolytic effects of aromatherapy massage in patients with breast cancer, it was reported that a significant reduction in anxiety levels was found in patients who received aromatherapy massage for 4 weeks ( 30 minutes for twice in a week) ${ }^{19}$. In conclusion, studies in the literature show that lavender oil applied by inhalation has the effect of reducing preoperative anxiety levels of patients. The results of our experiment revealed that either study or control group experienced parallel levels of anxiety in the preoperative period, but it was found that there was a significant difference between the pre-test and 
Volume: 2 Issue: 3

Year: 2021

DOI: $10.53811 /$ ijtcmr.988785
International Journal of Traditional and Complementary

Medicine Research
Publisher

Duzce University post-test state anxiety levels of the participants in the experiment group $(p=0.007)$. The increase in the post-test anxiety score average of the participants in the control group suggests that the anxiety levels in this group increased as the time of surgery approached. All results support the hypothesis that aromatherapy with essential oil inhalation reduces pre-operative anxiety levels. As a conclusion of our study managed to investigate the effect of lavender oil on preoperative anxiety levels of participants undergoing tympanoplasty surgery, it was concluded that aromatherapy with lavender oil inhalation had a positive effectiveness on preoperative anxiety control.

\section{REFERENCES}

1. Lehrner J, Marwinski G, Lehr S, Johren P, Deecke L. Ambient odors of orange and lavender reduce anxiety and improve mood in a dental office. Physiol Behav. 2005;86(1-2):92-95.

2. Lee YL, Wu Y, Tsang HW, Leung AY, Cheung WM. A systematic review on the anxiolytic effects of aromatherapy in people with anxiety symptoms. J Altern Complement Med. 2011;17(2):101-108.

3. Wotman M, Levinger J, Leung L, Kallush A, Mauer E, Kacker A. The Efficacy of Lavender Aromatherapy in Reducing Preoperative Anxiety in Ambulatory Surgery Patients Undergoing Procedures in General Otolaryngology. Laryngoscope Investig Otolaryngol. 2017;2(6):437-441.

4. Soltani R, Soheilipour S, Hajhashemi V, Asghari G, Bagheri M, Molavi M. Evaluation of the effect of aromatherapy with lavender essential oil on post-tonsillectomy pain in pediatric patients: a randomized controlled trial. Int J Pediatr Otorhinolaryngol. 2013;77(9):1579-1581.

5. Beyliklioğlu A, Arslan S. Effect of Lavender Oil on the Anxiety of Patients Before Breast Surgery. J Perianesth Nurs. 2019;34(3):587-593.

6. Saritaş S, Kavak F, Savaş B. The effect of lavender oil on anxiety levels of patients before laparoscopic cholecystectomy. Complement Ther Clin Pract. 2018;32:51-54.

7. Citlik Saritas S, Buyukbayram Z, Kaplan Serin E, Bilgic Y. Effects of lavender oil intervention before endoscopic retrograde cholangiopancreatography on patients' vital signs, pain and anxiety: A randomized controlled study. Explore (NY). 2020:S1550-8307(20)30229-9.

8. Spielberger CD, Gorsuch RL, Lushene R, Vagg PR, Jacobs GA. Manual for the State-Trait Anxiety Inventory. Palo Alto, CA: Consulting Psychologists Press; 1983.

9. Foley NM, O'Connell EP, Lehane EA, Livingstone V, Maher B, Kaimkhani S, Cil T, Relihan N, Bennett MW, Redmond HP, Corrigan MA. PATI: Patient accessed tailored information: A pilot study to evaluate the effect on preoperative breast cancer patients of information delivered via a mobile application. Breast. 2016;30:54-58.

10. Fındık ÜY, Topçu SY. Effect of the way of surgery on preoperative anxiety. Hacettepe Univ Faculty Health Sci Nurs J. 2012;19:22-33.

11. Şıvgın S. Elektif operasyon planlanan hastalarda psikolojik ve farmakolojik premedikasyonun preoperatif anksiyete düzeyi ölçülerek karşılaştırılması. İzmir, Türkiye: Dokuz Eylül Üniversitesi Tıp Fakültesi, Anesteziyoloji ve Reanimasyon Anabilim Dali; 2013.

12. Nasiri A, Mahmodi MA, Nobakht Z. Effect of aromatherapy massage with lavender essential oil on pain in patients with osteoarthritis of the knee: A randomized controlled clinical trial. Complement Ther Clin Pract. 2016;25:75-80.

13. Raisi Dehkordi Z, Hosseini Baharanchi FS, Bekhradi R. Effect of lavender inhalation on the symptoms of primary dysmenorrhea and the amount of menstrual bleeding: A randomized clinical trial. Complement Ther Med. 2014;22(2):212219.

14. Toda M, Morimoto K. Effect of lavender aroma on salivary endocrinological stress markers. Arch Oral Biol. 2008;53(10):964968.

15. Umezu T, Nagano K, Ito H, Kosakai K, Sakaniwa M, Morita M. Anticonflict effects of lavender oil and identification of its active constituents. Pharmacol Biochem Behav. 2006;85(4):713-721.

16. Shiina Y, Funabashi N, Lee K, Toyoda T, Sekine T, Honjo S, Hasegawa R, Kawata T, Wakatsuki Y, Hayashi S, Murakami S, Koike K, Daimon M, Komuro I. Relaxation effects of lavender aromatherapy improve coronary flow velocity reserve in healthy men evaluated by transthoracic Doppler echocardiography. Int J Cardiol. 2008;129(2):193-197.

17. Franco L, Blanck TJ, Dugan K, Kline R, Shanmugam G, Galotti A, von Bergen Granell A, Wajda M. Both lavender fleur oil and unscented oil aromatherapy reduce preoperative anxiety in breast surgery patients: a randomized trial. J Clin Anesth. 2016;33:243-249.

18. Boehm K, Büssing A, Ostermann T. Aromatherapy as an adjuvant treatment in cancer care--a descriptive systematic review. Afr J Tradit Complement Altern Med. 2012;9(4):503-518.

19. Imanishi J, Kuriyama H, Shigemori I, Watanabe S, Aihara Y, Kita M, Sawai K, Nakajima H, Yoshida N, Kunisawa M, Kawase M, Fukui K. Anxiolytic effect of aromatherapy massage in patients with breast cancer. Evid Based Complement Alternat Med. 2009;6(1):123-128. 